\title{
Evaluation of Thickness of Palatal Masticatory Mucosa in Relation with Age and Gender
}

\author{
Varun Choudhary, Manab Kosala, S. K. Bhandari \\ Department of Dental Surgery and Oral Health Sciences, Division of Periodontology, Armed Forces Medical College, Pune, \\ Maharashtra, India
}

Email for correspondence: drvarunchoudhary@gmail.com

\begin{abstract}
Background: Palatal masticatory mucosa is most commonly used as the donor site for harvesting of the subepithelial connective tissue graft for the selection of the treatment modalities, as it may affect the surgical outcome. Therefore, the present study was undertaken to evaluate the thickness of the masticatory mucosa in relation with age and gender. Materials and Methods: Fifty systemically healthy individuals were selected for the study. The younger age group consisted of 25 individuals aged 15-20 years and rest of the subjects was belonging to the older age group between 30 and 50 years. A bone sounding procedure was used to examine the palatal mucosal thickness. Results: The thickness of the masticatory mucosa ranged between 1.3 and $4.4 \mathrm{~mm}$ in all the subjects and it also showed variations in relation with age and gender. Conclusion: Therefore, it was concluded that younger individuals particularly females have significantly thinner mucosa as compared to males and older subjects.
\end{abstract}

Key words: Age, gender, masticatory mucosa

\section{INTRODUCTION}

The oral mucosa covering the hard palate constitutes of palatal masticatory mucosa, which is widely used as a donor material in various periodontal procedures that include periodontal plastic surgery for root coverage, for increasing the width of attached gingiva, and for ridge augmentation procedures. Therefore, the thickness of the masticatory mucosa is important for the selection treatment modalities since it may affect the surgical outcome.

Although several studies have previously investigated on the thickness regarding masticatory palatal mucosa, the majority of the subjects were edentulous and had complete dentures. Kydd et al. measured the thickness of oral mucosa at 12 palatal

Quick Response Code Article Info:

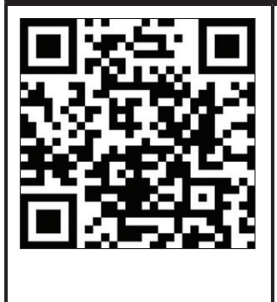

doi: 10.5866/2019.11.10022

Received: 08-01-2019

Revised: 05-02-2019

Accepted: 06-03-2019

Available Online: 01-04-2019, (www.

nacd.in)(C NAD, 2019 - All rights

reserved sites in patients using ultrasonic transducer and reported thickest palatal mucosa at the third molar area ranging from 3.9 to $4.0 \mathrm{~mm} .^{[1]}$

Another study done by Studer et al. measured the mucosal thickness by a bone sounding technique at the hard palate region and tuberosity in the healthy Caucasians with an average age of 35 years, which suggested that the gender did not influence the thickness of the masticatory mucosa. ${ }^{[2]}$ Müller et al. reported that female significantly had thinner mucosa than males and the thickest part was located in the molar and premolar regions measuring $3 \mathrm{~mm}$ or more on an average. ${ }^{[3]}$ Khatri et al. concluded that soft-tissue thickness progressively increased in sites further from the gingival margin and was thickest adjacent to midpalatal aspect of the second premolar $12 \mathrm{~mm}$ away from the gingival margin. Younger age group patients had thinner posterior palatal mucosa as compared to older age group patients. Males had thicker posterior palatal mucosa as compared to females, but results were statistically insignificant. ${ }^{[4]}$

Therefore, the present study was taken up to measure the thickness of the palatal masticatory mucosa in relation with age and gender by a bone sounding procedure. 


\section{MATERIALS AND METHODS}

\section{Study Population}

Fifty systemically healthy individuals ( 25 males and 25 females) who aged 15 and 50 years were selected for the study from the outpatient department at Government Dental Centre, Golconda. These individuals were divided into two age group categories. The younger age group consisted of 25 subjects aged 15-20 years, of which 13 were females, and the rest of the subjects belonged to the older age group between 30 and 50 years, of which 12 subjects were females. Patients fulfilling the following criteria were included in the study.

\section{Inclusion Criteria}

1. Periodontally healthy patients with no loss of attachment and no probing depth $>4 \mathrm{~mm}$.

2. The presence of complete dentition in the upper jaw with or without the third molar.

\section{Exclusion Criteria}

1. History of any palate or tuberosity surgery.

2. History or any present diagnosis of stomatological disease in the tuberosity.

3. Patients using medication possibly affecting the periodontal tissue, such as cyclosporine A, calcium channel blocker, or phenytoin.

4. Patients wearing any removable device in the upper arch such as a removable partial denture or orthodontic retainer.

5. Patients with fixed partial denture between the upper canine and second molar regions.

6. Patients with tooth malposition, rotation, or spacing in the upper arch.

\section{Assessment of Thickness of Palatal Mucosa}

During the first visit of the patient, an upper arch impression was taken using alginate impression material and study models with clear acrylic stent were fabricated. Fifteen measurement points were defined and marked on the study model for measuring the thickness of the masticatory mucosa. The palate was divided into two halves by line $\mathrm{p}$ which extends in the midline of the palate. Fifteen cross points were positioned on the canine, first premolar, second premolar, first molar, and second molar regions. The measuring points of canine were positioned at its midpalatal aspect, points at first and second premolar were present from their lingual cusps, and in case of first and second molars, the measuring points were present from the mesiolingual cusp of both the molars.
Line "a" was marked on the palate which represented the gingival margin, line " $\mathrm{b}$ " was marked $3 \mathrm{~mm}$ away from the gingival margin , and lines "c" and " $\mathrm{d}$ " were positioned one-fourth and half the distance between line "b" and line "p" respectively. With the help of a fissure diamond bur, holes were created at the marked measurement points on the stents. The stent provided a consistent location for the assessment of the mucosal thickness.

In the second visit, the stent was placed properly on the upper arch, and the 15 measurement points on the palate were marked with gentian violet-blue pencil according to the holes prepared on the stent. The thickness of the hard palate was assessed by first anesthetizing the palate with topical anesthetic ointment (2\% lignocaine hydrochloride) and then greater palatine nerve and incisive nerve were blocked with $0.1 \mathrm{ml}$ and $0.05 \mathrm{ml}$ of anesthetic solution, respectively (2\% lignocaine 1:100,0000 concentration epinephrine injection). 20 min after the injection, the thickness of the palatal mucosa was assessed by bone sounding procedures with a "Williams graduated periodontal probe" and a rubber stopper. The probe with the rubber stopper securely in place was then lined up to a $0.5 \mathrm{~mm}$ scale, sterile, stainless steel ruler. Two readings were obtained at each point, and the average of two measurements was used as the final measurement for the thickness at each location [Figure 1].

\section{RESULTS}

The results demonstrated that the thickness of the masticatory mucosa ranged between 1.3 and $4.4 \mathrm{~mm}$ in all the subjects. The thickness of the palatal mucosa ranged between 1.3 and $4.2 \mathrm{~mm}$ in case of younger age group with the mean thickness of $3.0 \pm 0.4 \mathrm{~mm}$, and in case of older age group, it ranged between 1.6 and $4.4 \mathrm{~mm}$ with the mean

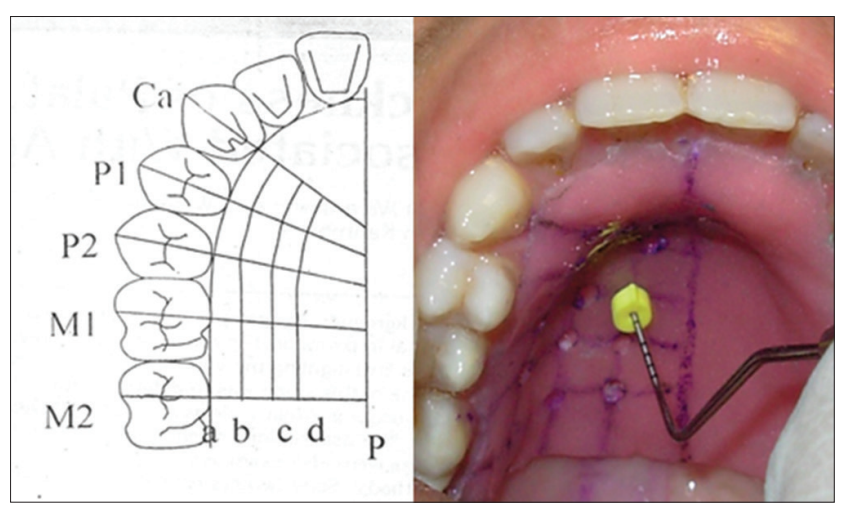

Figure 1: Assessment of thickness of palatal mucosa 
thickness of $3.7 \pm 0.3 \mathrm{~mm}$. Males belonging to the younger age group had mean thickness of $3.7 \pm$ $0.2 \mathrm{~mm}$ that ranged between 1.6 and $4.2 \mathrm{~mm}$ and females of the same age group had mean thickness of $2.4 \pm 0.3 \mathrm{~mm}$ that ranged between 1.3 and $3.0 \mathrm{~mm}$. In case of females, the older age group had mucosal thickness of $3.7 \pm 0.3 \mathrm{~mm}$ that ranged between 1.6 and $4.0 \mathrm{~mm}$ and males had mucosal thickness $3.9 \pm 0.4 \mathrm{~mm}$ that ranged between 2.2 and $4.4 \mathrm{~mm}$. Therefore, within the limits of the present study, it can be concluded that the mean thickness of the palatal masticatory mucosa ranged between
1.3 and $4.4 \mathrm{~mm}$ with no difference between males and females, and the younger individuals have significantly thinner mucosa than as compared to older subjects [Tables 1 and 2]. Mucosal thickness also increased from the canine to the second molar areas and all the sites further from the gingival margin toward the midline of the palate [Tables 3-5; Graphs 1-3].

\section{DISCUSSION}

The aim of the present study was to measure the thickness of the palatal masticatory mucosa

Table 1: Characteristics of the study population

\begin{tabular}{lccccccc} 
Characteristics & \multicolumn{3}{c}{ Age 15-20 } & & \multicolumn{3}{c}{ Age 30-50 } \\
\cline { 2 - 4 } \cline { 7 - 9 } & All & Females & Males & & All & Females & Males \\
\hline N subjects & 25 & 13 & 12 & & 25 & 12 & 13 \\
Mean age \pm SD & $17.5 \pm 0.2$ & $17.8 \pm 2.3$ & $17.6 \pm 3.2$ & & $40 \pm 3.6$ & $40.2 \pm 5.3$ & $47.5 \pm 4.5$ \\
\hline
\end{tabular}

Table 2: Mean score of palatal thickness by age group and gender at the subject level

\begin{tabular}{|c|c|c|c|c|c|c|c|c|c|}
\hline \multirow{2}{*}{$\begin{array}{l}\text { Mean mucosal } \\
\text { thickness (mm) }\end{array}$} & \multicolumn{3}{|c|}{ Age 15-50 $(n=50)$} & \multicolumn{3}{|c|}{ Age 15-20 $(n=25)$} & \multicolumn{3}{|c|}{ Age 30-50 ( $n=25)$} \\
\hline & All & Female & Male & All & Female & Male & All & Female & Male \\
\hline Mean $\pm \mathrm{SE}$ & $3.4 \pm 0.3$ & $3.0 \pm 0.3$ & $3.8 \pm 0.2$ & $3.0 \pm 0.4$ & $2.4 \pm 0.3$ & $3.7 \pm 0.2$ & $3.7 \pm 0.3$ & $3.6 \pm 0.2$ & $3.9 \pm 0.4$ \\
\hline Range & $1.3-4.4$ & $1.3-4.0$ & $1.6-4.4$ & $1.3-4.2$ & $1.3-3.0$ & $1.6-4.2$ & $1.6-4.4$ & $1.6-4.0$ & $2.2-4.4$ \\
\hline$P$-value & $\mathrm{S}$ & NS & NS & $\mathrm{S}$ & NS & NS & $\mathrm{S}$ & NS & NS \\
\hline
\end{tabular}

$\mathrm{S}=P \leq 0.05, \mathrm{NS}=P \leq 0.05$

Table 3: Thickness of palatal masticatory mucosa at five different regions (mean of three measurement points for each) in different age groups. ( $\mathrm{MV} \pm \mathrm{SD}$; in $\mathrm{mm}$ with range)

\begin{tabular}{|c|c|c|c|c|c|}
\hline Age group & Canine & First premolar & Second premolar & First molar & Second molar \\
\hline \multirow[t]{2}{*}{ All age groups (15-50 years) range } & $1.8 \pm 0.4$ & $2.4 \pm 0.5$ & $2.9 \pm 0.5$ & $3.3 \pm 0.6$ & $3.8 \pm 0.5$ \\
\hline & $1.5-2.0$ & $2.0-2.7$ & $2.5-3.2$ & $2.9-3.7$ & $3.5-4.2$ \\
\hline \multirow[t]{2}{*}{ Younger age group (15-20 years) range } & $1.5 \pm 0.3$ & $2.0 \pm 0.4$ & $2.5 \pm 0.5$ & $2.9 \pm 0.5$ & $3.5 \pm 0.5$ \\
\hline & $1.4-1.7$ & $2.0-2.2$ & $2.5-2.6$ & $2.9-3.0$ & $3.4-3.6$ \\
\hline \multirow[t]{2}{*}{ Older age group (30-50 years) range } & $2.0 \pm 0.3$ & $2.7 \pm 0.3$ & $3.2 \pm 0.3$ & $3.7 \pm 0.3$ & $4.2 \pm 0.2$ \\
\hline & $1.9-2.2$ & $2.7-2.9$ & $3.2-3.3$ & $3.7-3.0$ & $4.0-4.2$ \\
\hline$P$-value & $\mathrm{S}$ & $\mathrm{S}$ & $\mathrm{S}$ & $\mathrm{S}$ & $\mathrm{S}$ \\
\hline
\end{tabular}

$\mathrm{S}=P \leq 0.05$

Table 4: Thickness of palatal masticatory mucosa at 5 different regions (mean of three measurement points for each) for different $\operatorname{sex}(\mathrm{MV} \pm \mathrm{SD}$; in $\mathrm{mm}$ with range)

\begin{tabular}{|c|c|c|c|c|c|}
\hline Age group & Canine & First premolar & Second premolar & First molar & Second molar \\
\hline Male & $2.0 \pm 0.2$ & $2.7 \pm 0.2$ & $3.2 \pm 0.2$ & $3.7 \pm 0.1$ & $4.2 \pm 0.1$ \\
\hline Range & $1.9-2.3$ & $2.6-2.9$ & $3.2-3.4$ & $3.7-3.8$ & $4.2-4.3$ \\
\hline Range & $1.2-1.5$ & $2.0-2.1$ & $2.2-2.4$ & $2.2-2.6$ & $2.0-2.1$ \\
\hline$P$-value & NS & NS & NS & NS & NS \\
\hline
\end{tabular}

$\mathrm{NS}=P \leq 0.05$ 
in individuals aged $15-50$ years by direct clinical measurement. The gingival margin and the midpalatal line were used as fixed references to define 15 measurement points on the hard palate. This allowed reliable comparison of the mucosal thickness at each measurement points between the younger and the older subjects. A prepared clear acrylic stent was fabricated to ensure consistent locations for the repeated assessment of mucosal thickness.

The results demonstrated that the mean thickness of the palatal mucosa ranged between 1.3 and $4.4 \mathrm{~mm}$ among the participants, and the younger group had significantly thinner mucosa with the mean of $3.0 \pm 0.4 \mathrm{~mm}$ than the older age group with the mean of $3.7 \pm 0.3 \mathrm{~mm}$. Similar observations have been made by Wara-Aswapati et al., who reported the mean thickness of palatal mucosa ranged between 2.0 and $3.7 \mathrm{~mm}$ in $14-59$ years age group with significantly thinner mucosa $2.8 \pm 0.3 \mathrm{~mm}$ in younger age group (14-21 years) than the older age group (30-50 years) with the mean thickness of $3.1 \pm 0.3 \mathrm{~mm} .{ }^{[5]}$ Similarly, Khatri et al. reported that the younger age (16-24 yrs) group had significantly thinner mucosa $(3.28 \pm 1.17 \mathrm{~mm})$ than the older age $(25-38$ years $)$ group $(3.48 \pm 1.45 \mathrm{~mm})$ in relation to the posterior palatal mucosa. ${ }^{[4]}$ It is possible that the orthokeratinizing epithelial layer of the hard palate mucosa increases with age, resulting in the thicker palatal mucosa in the older subjects observed in the study. In addition, the hard palate possesses a submucosal layer, which contains various amount of adipose tissue and small mucous glands. There may be confounding factors that influences the palatal submucosal thickness such as racial, genetic factors, and body weight. It is not unreasonable to hypothesize that the body weight has an effect on the amount of adipose tissue in the palatal submucosal layer that results in an increased thickness of the palatal mucosa. In the present study, the majority of the older subjects appeared to have higher body mass indices on palatal mucosal thickness need to be further investigated.

In general, a free gingival graft is performed to correct mucogingival problems in young patients. The subepithelial connective tissue graft (SGCT) results in a better esthetic outcome but requires thicker donor palatal tissue than the free gingival graft procedure. Although the palatal mucosa of the younger age group was thinner than the older age group, the mucosal thickness of the younger 


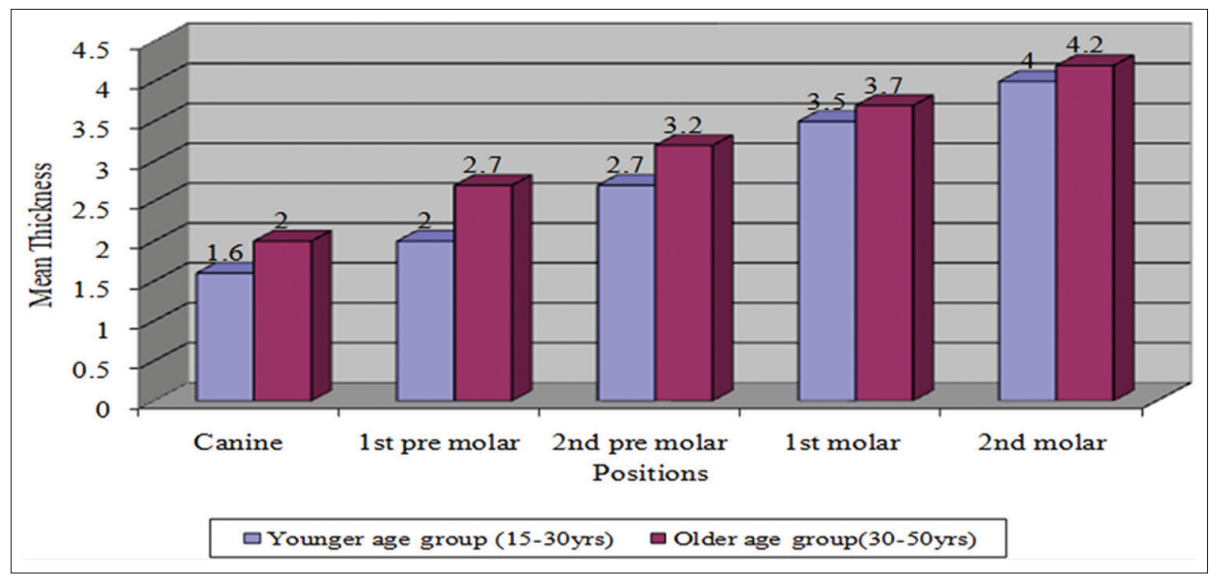

Graph 1: Comparison of thickness of masticatory mucosa of five regions in relation with age (younger age group and older age group)

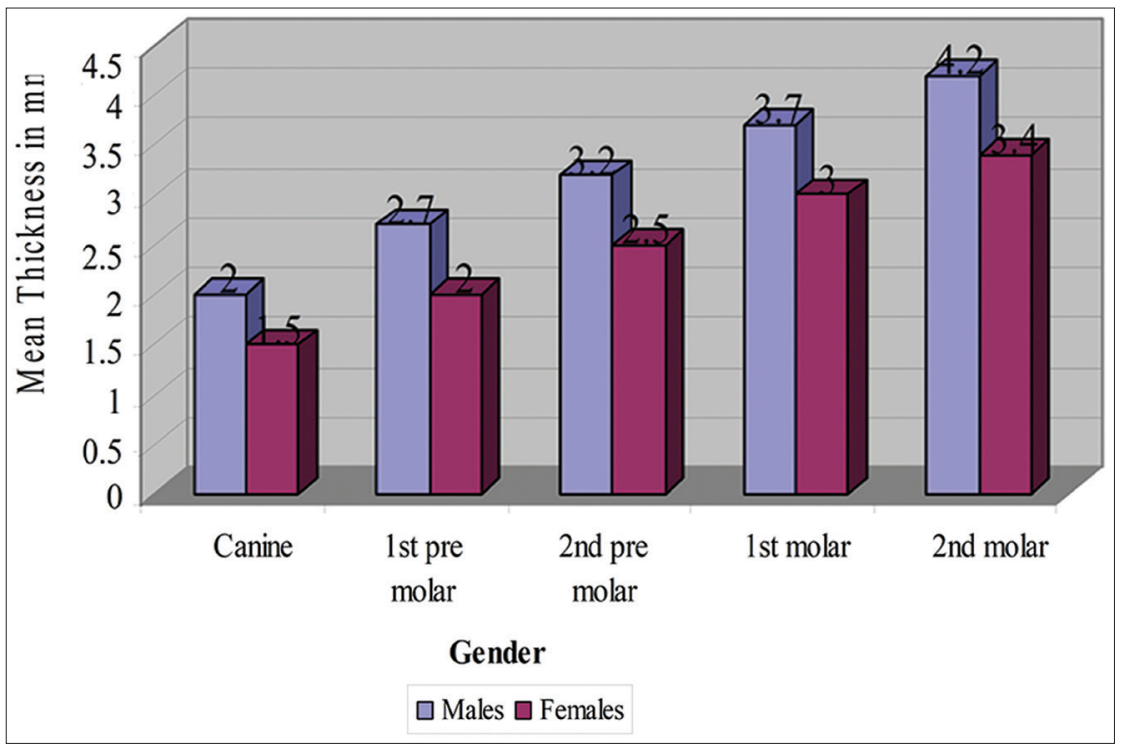

Graph 2: Comparison of thickness of masticatory mucosa in $\mathrm{mm}$ at five regions in relation with gender

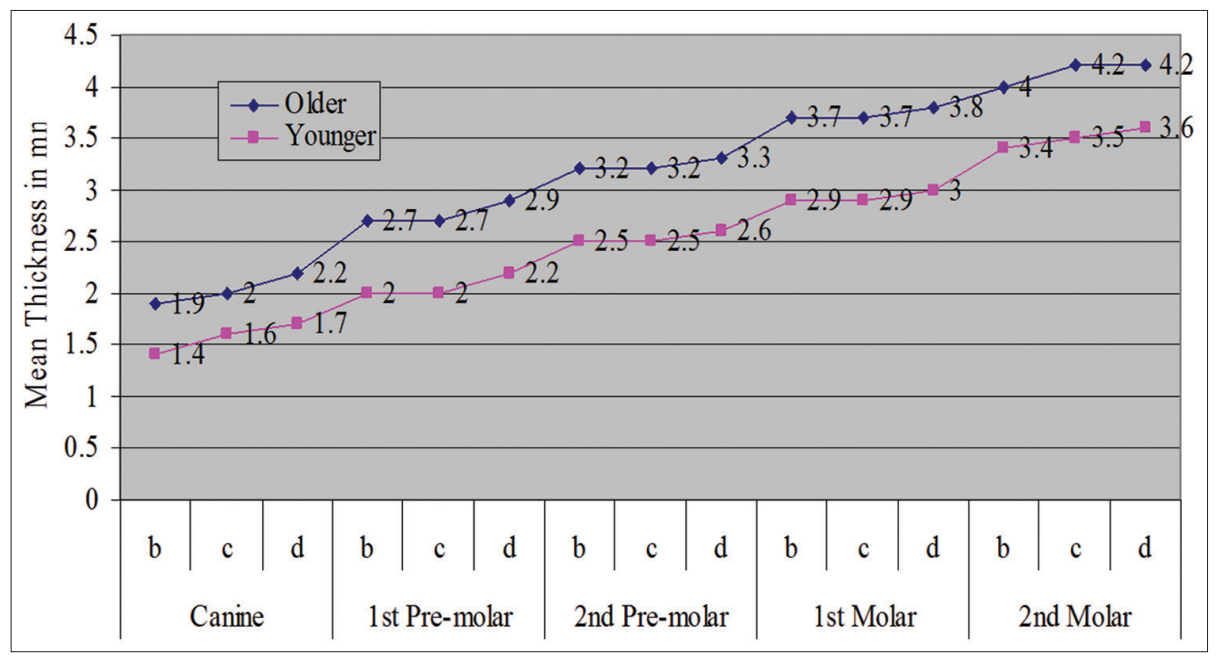

Graph 3: Mean thickness of mucosa in mm 
group ranged between 1.5 and $3.6 \mathrm{~mm}$, suggesting that a sufficient volume of palatal donor tissue can be obtained for the SGCT procedure in this patient group. Therefore, the SGCT procedure can be considered as a treatment modality in young patients.

The present study revealed no significant difference in tissue thickness between males and females. The results were in accordance to the study done by Müller et al., Song et al., Studer et al., Eger et al., Kuriakose and Raju, Wara-Aswapati et al., and Kolliyavar et al. and in contrast with the study done by Schacher et al. who stated that females had thicker mucosa than males which basically depends on body mass. ${ }^{[2,3,5-10]}$

In the present study, overall, the thickness of the palatal mucosa increased from the canine to the second molar areas and all the sites further from the gingival margin in both young and adult individuals. However, significant thinner mucosa was observed at first molar area on line "c" by Wara-Aswapati et al. and at line " $a$ " and " $b$ " in relation with first molar by Studer et al. ${ }^{[2,5]}$ Difference between these studies and present finding might be explained by different sites chosen for measurement. The palatal neurovascular bundle which is housed in a palatal groove and located at approximately 7 to $17 \mathrm{~mm}$ from cementoenamel junction of the upper molars depending on the shape of the palatal vault may have an effect on the measurement if the probe penetrates into neurovascular structures. ${ }^{[11]}$ Therefore, the present study suggests that the canine to the first molar region could to be the most appropriate donor site for grafting procedure in both the young and adult individuals.

\section{CONCLUSION}

The present study was undertaken to evaluate the thickness of masticatory mucosa in relation with age and gender. The results demonstrated that the thickness of the masticatory mucosa ranged between 1.3 and $4.4 \mathrm{~mm}$ in all the subjects with no difference between males and females, and the younger individuals have significantly thinner mucosa than as compared to older subjects. Mucosal thickness also increased from the canine to the second molar areas and all the sites further from the gingival margin toward the midline of the palate. The thickness of posterior palatal mucosa shows a varied degree of variation, and the difference in the mean thickness might be due to age, gender, ethnicity, varying measurement methods, and the placement of measurement points. The area of the palate from the distal line angle of the canine to the mesial line angle of the palatal root of the first molar provides a sufficient donor tissue for grafting procedures and also reduces the risk of violating the associated neurovascular structures.

Certain limitations were also observed in the study such as due to small sample size, statistical analysis was limited, and the mucosal thickness at the second molar region on line " $d$ " was not assessed accurately in some of the individuals, as the measurement site was located in the soft palate.

\section{REFERENCES}

1. Kydd WL, Daly CH, Wheeler JB $3^{\text {rd }}$. The thickness measurement of masticatory mucosa in vivo. Int Dent J 1971; 21:430-41.

2. Studer SP, Allen EP, Rees TC, Kouba A. The thickness of masticatory mucosa in the human hard palate and tuberosity as potential donor sites for ridge augmentation procedures. J Periodontol 1997;68:145-51.

3. Müller HP, Heinecke A, Schaller N, Eger T. Masticatory mucosa in subjects with different periodontal phenotypes. J Clin Periodontol 2000;27:621-6.

4. Khatri M, Gupta G, Puri K, Bansal M, Garg S, Ranga P. Evaluation of thickness of palatal masticatory mucosa in posterior teeth and its relation with age and gender. Indian J Dent Sci 2017;9:245-50.

5. Wara-aswapati N, Pitiphat W, Chandrapho N, Rattanayatikul C, Karimbux N. Thickness of palatal masticatory mucosa associated with age. J Periodontol 2001; 72:1407-12.

6. Song JE, Um YJ, Kim CS, Choi SH, Cho KS, Kim CK, et al. Thickness of posterior palatal masticatory mucosa: The use of computerized tomography. J Periodontol 2008;79:406-12.

7. Eger T, Müller HP, Heinecke A. Ultrasonic determination of gingival thickness. Subject variation and influence of tooth type and clinical features. J Clin Periodontol 1996; 23:839-45.

8. Kuriakose A, Raju S. Assessment of thickness of palatal mucosal donorsite and its association with age and gender. J Indian Soc Periodontol 2012;16:370-4.

9. Kolliyavar B, Setty S, Thakur SL. Determination of thickness of palatal mucosa. J Indian Soc Periodontol 2012; 16:80-3.

10. Schacher B, Bürklin T, Horodko M, Raetzke $P$, Ratka-Krüger $\mathrm{P}$, Eickholz $\mathrm{P}$, et al. Direct thickness measurements of the hard palate mucosa. Quintessence Int 2010;41:e149-56.

11. Reiser GM, Bruno JF, Mahan PE, Larkin LH. The subepithelial connective tissue graft palatal donor site: Anatomic considerations for surgeons. Int J Periodontics Restorative Dent 1996;16:130-7. 